\title{
The role of information and communication technologies in the delivery of health services in rural communities: Experiences from Malawi
}

\begin{tabular}{|c|c|}
\hline \multicolumn{2}{|c|}{$\begin{array}{l}\text { Authors: } \\
\text { Chimango Nyasulu } 1 \text { (1) } \\
\text { Winner D. Chawinga }{ }^{2}\end{array}$} \\
\hline \multicolumn{2}{|c|}{$\begin{array}{l}\text { Affiliations: } \\
{ }^{1} \text { Department of Information } \\
\text { and Communication } \\
\text { Technology, Mzuzu } \\
\text { University, Malawi }\end{array}$} \\
\hline \multicolumn{2}{|c|}{$\begin{array}{l}{ }^{2} \text { Department of Library and } \\
\text { Information Science, Mzuzu } \\
\text { University, Malawi }\end{array}$} \\
\hline \multicolumn{2}{|c|}{$\begin{array}{l}\text { Corresponding author: } \\
\text { Chimango Nyasulu, } \\
\text { chimangoh@gmail.com }\end{array}$} \\
\hline \multicolumn{2}{|c|}{$\begin{array}{l}\text { Dates: } \\
\text { Received: } 12 \text { June } 2017 \\
\text { Accepted: } 08 \text { May } 2018 \\
\text { Published: } 18 \text { Sept. } 2018\end{array}$} \\
\hline \multicolumn{2}{|c|}{$\begin{array}{l}\text { How to cite this article: } \\
\text { Nyasulu, C. \& Chawinga, } \\
\text { W.D., 2018, 'The role } \\
\text { of information and } \\
\text { communication technologies } \\
\text { in the delivery of health } \\
\text { services in rural communities: } \\
\text { Experiences from Malawi', } \\
\text { South African Journal of } \\
\text { Information Management } \\
\text { 20(1), a888. https://doi. } \\
\text { org/10.4102/sajim.v20i1.888 }\end{array}$} \\
\hline \multicolumn{2}{|c|}{$\begin{array}{l}\text { Copyright: } \\
\text { (C) 2018. The Authors } \\
\text { Licensee: AOSIS. This } \\
\text { is licensed under the } \\
\text { Creative Commons } \\
\text { Attribution License. }\end{array}$} \\
\hline \multicolumn{2}{|l|}{ Read online: } \\
\hline 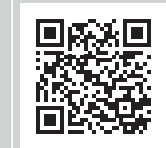 & $\begin{array}{l}\text { Scan this QR } \\
\text { code with your } \\
\text { smart phone or } \\
\text { mobile device } \\
\text { to read online. }\end{array}$ \\
\hline
\end{tabular}

Background: In recent years, Africa has experienced a boom in information and communication technologies (ICTs). These ICTs have been hailed by the health sector as impetus for heath service delivery in rural areas. In this regard, stakeholders in the health sector have made attempts to reinforce frontline health workers with technological tools. Although there is much evidence that ICTs play a key role in the health sector, it remains unknown how the health sector in Malawi is exploiting ICTs in its delivery of day-to-day operations.

Objectives: In this study, we investigate the role that ICTs play in rural health. This study will specifically determine the purposes that health surveillance assistants (HSAs) use ICTs for, assess the ICT skills and expertise of HSAs, analyse benefits of ICTs and study the problems faced by HSAs in the effective use of ICTs.

Method: In this study, a quantitative research method approach was adopted to address the research objectives. Both research sites and respondents were selected using a convenient sampling method. We self-administered and collected the questionnaire from the respondents. The Statistical Package for the Social Sciences (SPSS) was used to analyse the data.

Results: We find that HSAs have made headways in the adoption of various forms of ICTs such as mobile phones alongside their applications (Facebook, Twitter and WhatsApp). However, efforts to maximise the appropriation of ICTs by HSAs are punctuated by various hindrances including high cost of ICT gadgets, high cost of Internet bundles, inadequate training in ICTs and lack of support from senior management in the Ministry of Health.

Conclusion: Use of ICTs in community health is slowly but surely possible. In a nutshell, the study has shown that, regardless of perceivable hindrances associated with use of ICTs, HSAs use some ICTs in their work and personal activities. It is evident that using mobile phones to improve performance is an important area and that there is little interest in evaluating such interventions.

\section{Introduction}

There is more interest in the research community regarding how information and communication technologies (ICTs) are used to stimulate development. For example, ICT is reported to improve health, education and the economic status of people in the developed and developing nations (Ramachandran et al. 2010). Use of ICTs improves service delivery in various ways such as increasing accessibility to basic needs, maximising service delivery, providing a conducive environment for discovery and transfer of upcoming technologies and products, increasing efficiency by providing increased connectivity and sharing of knowledge and enabling regions to dwell on providing services and accessibility of digital development for ongoing advancement (Ruxwana, Herselman \& Conradie 2010). Mostly, inclusion and assimilation of different forms of ICTs into daily health care workers life is undeniably becoming a reality across the globe (World Health Organization [WHO] Report 2004).

Health issues in developing countries are a top development priority (Quaglio et al. 2016). In developing nations, the health care condition is very poor, and it is a challenging issue mostly in providing health care services to people living in rural and remote areas (Shekar \& Otto 2014). Eleven per cent of the world's population is projected to be in Africa with estimated $22 \%$ of the global disease burden, and there is need of additional 1.5 million health workers to fill the existing human resource gap (Shekar \& Otto 2014). Information and communication technologies have a growing influence on all areas of human life and the health care sector is not spared (Nair 2014). 
Over the last decade, the use of ICTs has expanded considerably in low- and middle-income countries (LMICs) (Quaglio et al. 2016). For example, the rapid adoption of mobile phones in LMICs has far exceeded expectations. For instance, by the end of 2015, there were over 7 billion mobile cellular users worldwide, translating to a penetration rate of $97 \%$ worldwide. In developed and developing nations, penetration rates were $121 \%$ and $90 \%$, respectively. Internet accessibility has been increasing in LMICs, reaching 35\% in 2015. Quick developments in ICT-dependent applications in LMICs have renewed the attention of donors towards ICTs.

\section{The health sector in Malawi: Some brief facts}

Both public and private sectors offer health care services in Malawi (Ministry of Health [MoH] 2011). The public health sector consists of all health facilities that are managed by the $\mathrm{MoH}$ and Ministry of Local Government and Rural Development (MoLGRD); others are those managed by the Ministry of Education Science and Technology, the Department of Malawi Defense Force and the Department of Police and the Department of Prison Service (MoH 2011). The private sector includes profit-oriented and non-profit-oriented providers, which are managed by the Christian Health Association of Malawi (CHAM) which finances most of these health service providers (MoH 2011). The Christian Health Association of Malawi is the biggest non-governmental organisation that sponsors most private health care institutions such as hospitals offering health services to Malawians (CHAM 2017). Thirtyseven per cent of Malawi's health care training institutions are sponsored by CHAM, and these institutions train up to $80 \%$ of Malawi's health care workers (CHAM 2017). The public sector offers services for free, while the private sector offers its services at a fee (MoH 2011). Ministry of Health headquarters overlook the development of health policies, standards and protocols, and it is mandated to provide technical support required for monitoring Malawi's health sector.

\section{Categories of heath service delivery in Malawi}

Health services in Malawi are provided at three distinct levels, which include primary, secondary and tertiary levels. These levels are linked using a well-established referral system that operates within the health system (MoH 2011). Primary level constitutes the community initiatives, health posts, dispensaries, maternity facilities, health centres and community and rural hospitals. Community-based workers such as health surveillance assistants (HSAs), communitybased distributing agents, village health committees and volunteers offer services at community level. District hospitals constitute the secondary level of health care. Health centres and rural hospitals refer their patients to these district hospitals and are capable of admitting 200-300 patients. They also offer in-patient and out-patient services to the local communities. The tertiary level consists of central hospitals that offer referral health services for their regions.
Currently, there are four central hospitals in Malawi and they include Queen Elizabeth in Blantyre with a capacity of 1250 beds, Kamuzu Central Hospital in Lilongwe with a capacity of 1200 beds, Mzuzu Central Hospital in Mzimba district with a capacity of 300 beds and Zomba Central Hospital in Zomba district with a capacity of 450 beds (MoH 2011).

\section{Health surveillance assistants: What is their hierarchy in the health system in Malawi?}

According to Voluntary Service Overseas (VSO) Malawi (2011), HSAs form the largest health workforce in Malawi. Over 10000 HSAs work in rural areas of all 28 districts in Malawi (VSO Malawi 2011). Health surveillance assistants are frontline health providers and they are an important link between the health facility and the communities that they service (Kok \& Muula 2013). These HSAs directly interface with the local community on behalf of the $\mathrm{MoH}$. The minimum requirement to be employed as HSA is the Malawi Secondary Certificate Examinations (MSCE) or Junior Certificate Examination (JCE). This is in addition to an 8-week formal training programme on primary health (Kok \& Muula 2013). As already stated, HSAs act as a link between district hospitals and urban-based health centres with the rural communities. As such, information and emerging ideas from the $\mathrm{MoH}$ headquarters to be implemented at community level in the preventive health sector are implemented via the catalytic functions of HSAs (Kadzandira \& Chilowa 2001).

\section{Problem statement and objectives of the study}

In Malawi, efforts have been made by health stakeholders to advocate the deployment of ICTs such as mobile technologies in the delivery of health services to the communities $\mathrm{MoH}$ 2011). In all the three geographical regions of Malawi, automation has been initiated in central hospitals, specialist hospitals, and some district hospitals with an extension to some health centres (Luke International 2016). The application of ICT has positively impacted the delivery of services in these hospitals although it remains unclear how ICTs have affected the delivery of such services in community health (Luke International 2016).

However, little systematic analysis has been performed to help understand the use of ICTs in community health in Malawi. Therefore, this study sets out to investigate how ICTs are being utilised by HSAs, an important and unique group of health personnel that directly interfaces with the citizenry at community level.

The main objective of this study is to analyse the use of ICT in community health in two selected areas in Malawi. In order to achieve the main objective of this study, the following objectives were generated:

- to determine the purposes that HSAs use ICTs for

- to assess the ICT skills and expertise of HSAs 
- to analyse benefits of ICTs

- to find out the problems faced by HSAs in adoption and use of ICTs.

\section{Literature review}

In this section, we review related studies in the use of ICTs by health personnel. Our review is conducted in line with the following themes: purposes that HSAs use ICTs for, ICT skills and expertise of HSAs benefits of ICTs in community health and challenges that affect adoption and use of ICTs by HSAs.

\section{Case studies of information and communication technology initiatives in health delivery}

The Department for HIV and AIDS in 2005 under the $\mathrm{MoH}$ in Malawi formed a task force which aimed at investigating the possibility of using computers to record patient data and produce different reports at various antiretroviral therapy (ART) clinics (Douglas et al. 2010). Two electronic medical record (EMR) possible models were identified. The first model proposed the use of a clerk to capture patient data from patient treatment cards into one designated desktop computer. The second model proposed the use of networked computers connected to a central server that stored the information. The latter model meant that health care workers were to use touchscreen computers to capture patient data during clinical interaction at point-of-care. The task force recommended the second model with respect to the past experiences of using touchscreen systems in different domains in health care in Malawi since 2001. At Queen Elizabeth Central Hospital (QECH), ART clinic trial phase was implemented in April 2006 with funding from Global AIDS Program of the Centres for Disease Control and Prevention in Malawi. The task force opted for QECH because it was difficult to manually produce quarterly reports on time because of high patient burden. Patient treatment cards and clinic registers were running in parallel with EMR until there was enough proof that EMR was performing properly.

In India, Nair (2014) reports that the planning commission formed a steering committee on health which proposed in the plan (2012-2017) that telemedicine, Skype and audiovisual media should be used to link all district hospitals, primary health centres and subcentres to leading tertiary care centres. The committee recommended prioritising M-health, which is the use of mobile phones delivering health services.

\section{Common information and communication technologies used by health workers}

A study conducted in Nigeria by Jimoh et al. (2012) showed that most midwifes preferred decision support applications, whereas most community health extension practitioners opted for an application that enables quicker and easy access of individual patient history with minimal record duplications. As cited in Lucas (2008), WHO (2006) survey showed that over $80 \%$ of non-Organisation for Economic and Co-operation
Development (OECD) member states were of the view that electronic health records (EHRs), patient information systems, hospital information systems, national electronic registries, national drug registries, decision support systems and geographical information systems were useful forms on ICTs in the health sector. The Organization for Economic and Co-operation Development is a special forum that constitutes 34 countries of democracies with common market economies and over 70 non-member economies that strive to boost economic growth, prosperity and sustainable development (OECD 2017).

A study by Ahlan and Ahmad (2014) shows that EHR, EMR, computerised physician order entry (CPOE) and clinical decision support system are forms of health information technology (HIT) common in developing countries. Some of the HITs currently in use include a computerised system that is used for control of drug logistics in Brazil, EMR in Malawi, highly active ART in Botswana, partners in health in Peru, HIV-EMR in Haiti, PEPFAR project in Tanzania, Mosoriot Medical Record System in Kenya and Careware System in Uganda. Although a number of hospital information systems, district health information systems (DHIS), telemedicine, patient portals and OpenMRS are available in Africa, they are neither well known nor mostly used in most developing rural communities (Ruxwana et al. 2010).

\section{Purposes that information and communication technologies serve in health service delivery}

Literature shows that there are a number of purposes that a plethora of ICTs serve in health service delivery. A study by Lucas (2008) reveals four broad areas where ICT applications are considered useful in the health sector. They include improvements in traditional health information systems; diagnosis that is computer-aided and treatment monitoring and use of ICT to disseminate information to general populations on health and health care. A more promising area where ICT applications can be applied is concerned mainly with increasing access by communities to health information (Lucas 2008). Nair (2014) states that:

patients access better information on treatments, on their condition, and on better standards of living through e-health and that e-health systems simplify health workers' communication process for sharing of general and patient related information. (p. 3)

A study by Miah, Hasan and Gammack (2016) shows that cloud computing assists health care workers to monitor and maintain patient's health records, keeping in touch with patients and other practitioners, diagnosing or analysing health conditions of patients and also increasing awareness of patients on diseases or appropriate care.

\section{Skills of health workers in using information and communication technologies}

Many researchers have studied how ICTs support health professionals in developing regions. Most studies have pointed out that shortage of ICT-related skills and awareness amongst 
health workers are some of the key challenges (Ruxwana et al. 2010). There is usually shortage of health workforce in rural areas. Worse still, in areas where the health workers are available, their welfare is not taken seriously, with the lack or training support by their seniors thereby leaving them demotivated and resulting in a poor quality of care delivered (Shekar \& Otto 2014)

\section{Challenges that affect health worker's adoption and use of information and communication technologies}

The challenges that health workers face are too complex because some challenges such as limited resources cannot be dealt with overnight. A study by Jimoh et al. (2012) found that there were substantial differences in composite scores amongst health worker groups concerning perceived usefulness and challenges to technologies attributing the current scenario to low education levels and awareness of ICT. Jimoh et al. (2012) report further that some ICTs are often forced on end users without an understanding of the nature of solutions required by users.

Other challenges reported in the literature include lack of computer awareness amongst the majority of the rural communities, shortage of skilled and qualified people to manage the operation and functioning of ICT facilities and computer failures and damage of information because of viruses and frequent unstable power supply (Omona \& IkojaOdongo 2006). Unsustainable ICT projects because of overdependency on donor support, mean that the projects do not continue as soon as donors stop providing support. Another notable problem related to use of ICT in the health sector is lack of access to health information and dissemination (Omona \& Ikoja-Odongo 2006). In South Africa, for example, it is reported by Ruxwana et al. (2010) that use of ICTs in rural areas is affected by factors such as low literacy levels, professional isolation and lack of infrastructure, services and expertise and resources (Ruxwana et al. 2010).

\section{Theoretical framework: Technology acceptance model}

Most researchers have used the technology acceptance model (TAM) to study perception and factors contributing to acceptance or rejection of a new technology (Lucas 2008). Davis (1989) developed the TAM model to identify factors that prompt people to accept or reject a technology. Davis (1989:3) states that 'perceived usefulness' and 'perceived ease of use' are the two factors that influence people to reject or accept using an information technology.

Davis (1989:4) defined perceived usefulness as 'the degree to which a person believes that using a particular system would enhance his or her job performance'. Perceived ease of use is defined as 'the degree to which a person believes that using a particular system would be free of effort' (Davis 1989).

These two factors, 'perceived usefulness' and 'perceived ease of use', then influence one's behaviour towards acceptance or rejection of a technology. The researcher adopted TAM in the current study because of the variables of 'perceived usefulness' and 'perceived ease of use' outlined in the model. In their responsibility as a link between the community and the formal health service system, HSAs continue to seek for excellence through the use of different ICT support systems in this technology era.

Various studies have previously used the TAM to investigate the adoption of ICTs in various areas within the health sector (Ahlan \& Ahmad 2014; Chow et al. 2012; Gagnon et al. 2012; Holden \& Karsh 2010; Yarbrough \& Smith 2007). A study was conducted by Ahlan and Ahmad (2014) who used TAM to understand peoples' readiness and attitude towards the use of technology in self-diagnosis to reduce cost and improve quality in the health sector in Norway. In a related study, Chow et al. (2012) used TAM to describe and evaluate a virtual environment, which is the online three-dimensional world second life for learning rapid sequence intubation in health care. While the study found the system useful, thereby encouraging students to adopt the technology, students remained neutral regarding the TAMs construct of ease of use of the technology (Chow et al. 2012). Gagnon et al. (2012) used TAM to examine the factors that influenced the decision of health care professionals to use a telemonitoring system. The study revealed that TAM's perceived usefulness influenced respondents to adopt telemonitoring. As other constructs of TAM did not influence health professionals to adopt telemonitoring, the researchers proposed and developed another model as an extension to the TAM. Yarbrough and Smith (2007) conducted a systematic review on ICT acceptance by physicians by focussing on the studies that used the TAM as a model. They argued that TAM needs to be expanded to include organisational, system-specific and health carespecific factors. Another systematic review of literature was conducted by Holden and Karsh (2010), who reviewed studies on the adoption of information technologies by health professionals and interpreted the findings using the TAM model. The study revealed that TAM predicts a substantial portion of the use or acceptance of HIT, but recommended the need to make some modifications and additions to the model.

\section{Research methods}

In this study, the quantitative research method approach was adopted to address the research objectives. The study was conducted at Mapale Hospital and Madisi Mission Hospital. Mapale Hospital is located in Mzimba district under Mzimba North district Health Office, whereas Madisi Mission Hospital is located in Dowa district under Dowa district Health Office. Madisi Mission Hospital has 24 HSAs in total with 17 female HSAs and 7 male HSAs (O. Lunda, pers. comm., 10 December 2016), whereas Mapale Hospital has a total of 44 HSAs with 35 female HSAs and 9 male HSAs (K. Kaonga, pers. comm., 20 December 2016). Aliaga and Gunderson (2000:3) define a quantitative research as a research that involves 'explaining phenomena by collecting numerical data that are analysed using mathematically based methods (in particular statistics)'. We adopted a quantitative design because of its flexibility in terms of data collection and 
analysis as argued by Creswell (2009), who says that data collected through quantitative methods provide information that can easily be analysed statistically to generalise both explicit and implicit claims.

We used convenient sampling (Patton 2002:240) to select both research sites and participants. For research sites, we chose the two hospitals because of two key reasons. Firstly, the hospitals are the meeting places for rural-based HSAs where they meet once every month to submit reports to their supervisors and to collect health equipment for use in the rural areas they serve. Secondly, the two hospitals were convenient to us because they are located in urban areas meaning it was easier for us to travel to these places. The study included HSAs only because they directly interact with the rural population on health issues. Health surveillance assistants provide various health services such as managing under-five clinics; recording statistics of new pregnancies, births and deaths; administering contraceptive drugs; teaching people good sanitation practices; disease control (distributing free mosquito nets and purifying water with chlorine); giving first aid treatment and referring patients to hospitals; reporting emergencies administering drugs that do not require specialist prescriptions (e.g. pain killers); and recording population statistics in their catchment areas that are, in turn, used by the $\mathrm{MoH}$ for planning purposes. These HSAs live in rural areas where transport is a huge problem implying that communicating with their supervisors who are based in urban areas becomes a problem. Our assumption was that despite HSAs being geographically separated from their supervisors who live in urban areas, ICTs could be a catalyst to breaking the communication barrier resulting from geographical landscape and lack of transport because of poor road network. In this case, we distributed questionnaires to HSAs who were present at a monthly meeting they attended at the two hospitals in the month of January in 2017. The HSAs who were not present during the day and time the questionnaire was administered did not participate in the study because we envisaged that it could not be feasible for us to trace and visit each HSA in their duty stations, which are located in very typical rural areas.

Being a quantitative research, we designed a questionnaire which we self-administered to a total of 50 HSAs drawn from Mapale Hospital and Madisi Mission Hospital. We arranged with the heads of the hospitals to distribute the questionnaire to the respondents during the day the HSAs visit the hospitals. In that regard, it was easy for us to self-administer to and collect questionnaires to many respondents who gathered at Mapale Hospital and Mponela Mission Hospital.

The questionnaire, accompanied by a covering letter, explained the research topic and emphasised for the respondents that the information provided was going to remain confidential and meant for research purpose only. The questionnaire was divided into the following sections: general information, purpose HSAs use ICTs for and problems HSAs face when using ICTs and ICT skills. As a quantitate approach was adopted, the questionnaire contained close-ended questions.
The general information section was tailored to explore age, marital status, highest academic qualification, length of service and estimated population served. The purposes HSAs use ICTs for was tailored to explore HSA's awareness of ICT devices that included basic phone, smartphone, laptop computer, desktop computer, photocopier, printer and scanner. The section also explored awareness of the following ICT applications: DHIS, Facebook, WhatsApp, Twitter, Skype, short messaging system (SMS), search engines (e.g. Google), emailing system (e.g. Gmail and Yahoo mail) and cloud computing (Drop Box and Google Drive). The section further explored personal and work usage of the mentioned ICT applications. The ICT skills section explored the level of competence ranging from very good to not competent at all in using the ICT devices and ICT applications. The problems HSAs face when using ICTs section was tailored to find out the challenges faced in adopting and using ICTs for work purposes.

Data analysis is the stage at which the gathered data are transformed into information (Mouton 2001:108). The Statistical Package for the Social Sciences (SPSS) 20 was used to capture raw data and to execute the percentages and frequencies. Some frequencies and percentages were imported from SPSS to Microsoft Excel to produce figures and tables. Frequency and percentage distributions were depicted in tables and charts.

\section{Results and discussion}

In this section, we present and discuss the findings based on the data we collected from HSAs using a questionnaire. Apart from demographic information, we present and discuss the findings according to the themes underpinning this study as follows: ICT skills and expertise, purpose HSAs use ICTs for, problems HSAs face when using ICTs and benefits of using ICTs. We distributed a questionnaire to 50 HSAs, of whom 43 (86\%) responded. Of the 43 (86\%) questionnaires, 20 (46.5\%) were completed by HSAs from Madisi Mission Hospital, whereas 26 (60.4\%) questionnaires were completed by HSAs from Mapale District Hospital.

\section{Demographic and general information}

As depicted in Figure 1, the HSA sample consisted of more females with a score of $27(63 \%)$ compared to $16(37 \%)$ males. Twenty-four (55\%) respondents had an experience of between 6 and 10 years, whereas seven $(16 \%)$ had an experience of between 11 and 15 years. Figure 1 shows further that 29 (67\%) respondents were aged between 31 and 40 followed by 11 (25\%) who were aged between 41 and 50 . As previously reported by Chawinga and Zozie (2016), the education system in Malawi follows the 8-4-4 systems; in this case, 8 refers to minimum years required to complete primary school, 4 refers to minimum years required to complete secondary school and the last 4 refers to minimum years required to complete universities. The Malawi government recommend minimum of 6 years as the de facto age for starting primary education. It is, therefore, not surprising that the study did not record a significant number of respondents with ages between 20 and 30 . 


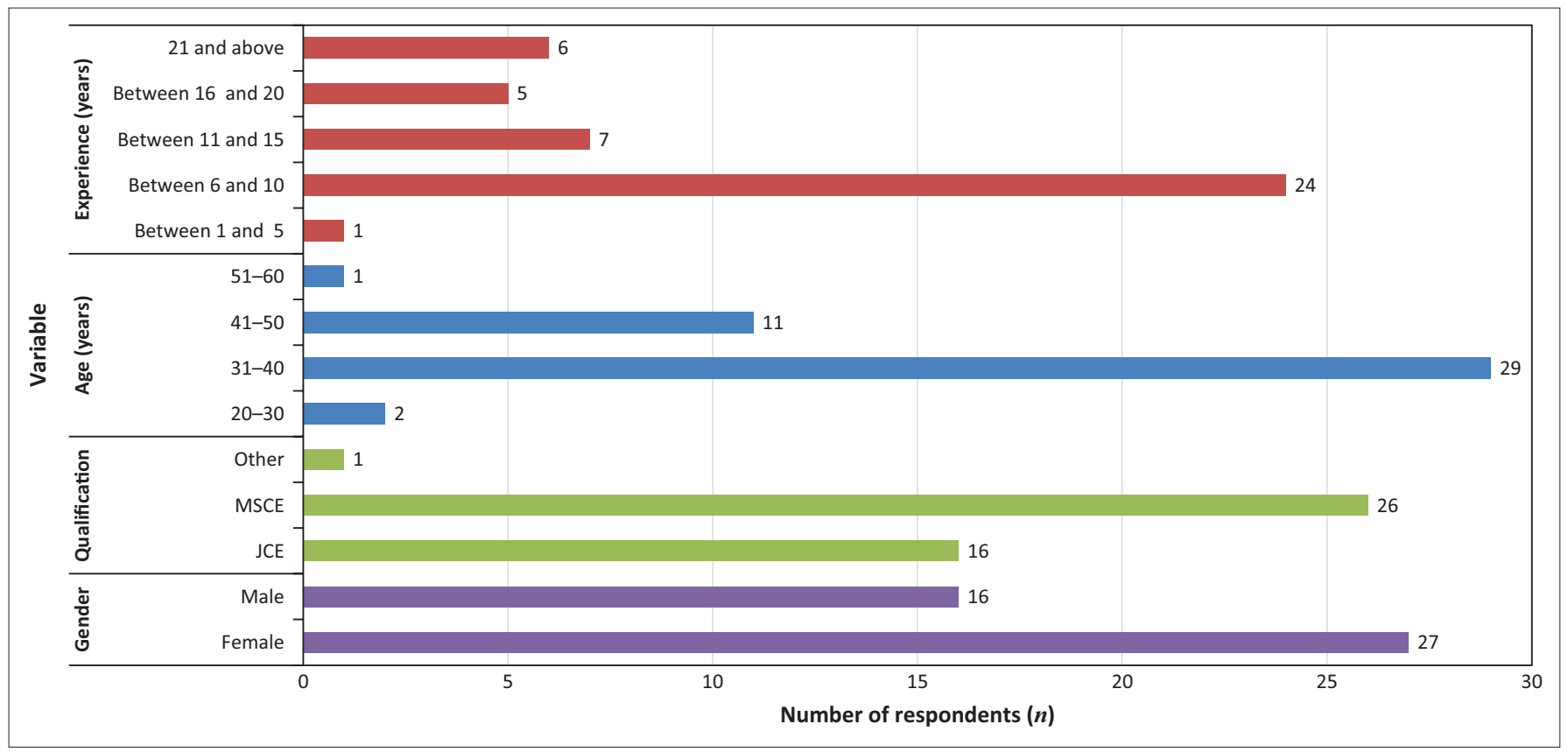

FIGURE 1: Background information of respondents $(n=43)$.

\section{Information and communication technology skills and expertise of health surveillance assistants in using information and communication technology devices}

The HSAs were asked to indicate their competencies in using ICT devices. The respondents were required to select from very good, good, average, poor to not competent at all. The researchers provided the HSAs with a list of ICT devices from which they were required to select the level of competence in using the ICT devices. The respondents were required to select from very good, good, average, poor to not competent at all. Table 1 depicts the respondents' level of competencies. As can be seen in Table 1, it is clear that $41(95.3 \%)$ respondents were competent in using a basic phone, $28(65.1 \%)$ respondents were competent in using smartphone, $12(27.9 \%)$ respondents were competent in using a desktop computers and nine $(20.9 \%)$ were competent in using flash disks. The findings reveal that overall, HSAs possess adequate skills for using basic phones and smartphones. Good levels of competencies by HSAs can be attributed to availability of ICT devices such as basic smartphones and the Internet in Malawi which, according to Chaputula (2012) and Chawinga and Zinn (2015) a are rapidly proliferating. The other reason could be attributed to the fact that some non-governmental organisations such as Luke International in collaboration with Mzuzu University hold joint periodic short courses aimed at equipping HSAs with basic ICTs skills. Davis (1989) proposed in their TAM that ease of use and resource availability influence users to adopt technologies. In this context, HSAs adopted ICTs in their work places because they had skills to use them and that these ICTs are available in Malawi.

We also provided respondents with a list of web-based applications from which they were required to select the level of competence in using these applications. Results presented in Table 2 show that $20(46.5 \%)$ were competent in using DHIS, 21 (48.8\%) were competent in using Facebook, $29(67.4 \%)$ were competent in using WhatsApp, four (9.3\%) were competent in using Twitter, 24 (51.2\%) were competent in using SMS, three (7.0\%) were competent in using Skype and eight $(18.6 \%)$ were competent in using Internet. Based on these findings, it is plausible to conclude that most HSAs possess adequate skills in using Facebook and WhatsApp as compared to other web applications. This can be attributed to the proliferation of smartphones in Malawi as reported by Chawinga (2016) and Chawinga and Zinn (2015, 2016). These smartphones have web applications such as Facebook and WhatsApp pre-installed or can be easily downloaded and installed. The other contributing factor is that Internet. org in partnership with Facebook provides free Internet to some web-based applications, thereby enabling most Malawians access to a variety of free basic web-dependent services like news on local jobs; and information on maternal health, travel, local government information, sports and communication (Facebook 2017). According to Chawinga and Zozie (2016), in Malawi, Internet service providers such as Internet cafés, which are mostly located in urban areas, charge higher user fees. That is the reason why most HSAs decide to use Facebook and WhatsApp, which are deemed to be cheaper a because in Malawi, network service providers do provide customised data bundles to suit needs of their customers. Surprisingly, the findings of the current study reveal that only a few HSAs were aware and competent in using Internet despite the fact that most of the stated ICTs run on the Internet. This suggests that HSAs do not know that web-based applications such as WhatsApp and Facebook are made possible by a connection to the Internet; they think that these applications work independently from the Internet. 
TABLE 1: Competence of health surveillance assistants in using information and communication technology devices $(n=43)$.

\begin{tabular}{|c|c|c|c|c|c|c|c|c|c|c|}
\hline \multirow[t]{2}{*}{ ICT devices } & \multicolumn{2}{|c|}{ Very good } & \multicolumn{2}{|c|}{ Good } & \multicolumn{2}{|c|}{ Average } & \multicolumn{2}{|c|}{ Poor } & \multicolumn{2}{|c|}{ Not competent at all } \\
\hline & $f$ & $\%$ & $f$ & $\%$ & $f$ & $\%$ & $f$ & $\%$ & $f$ & $\%$ \\
\hline Basic phone & 25 & 58.1 & 13 & 30.2 & 3 & 7.0 & 0 & 0.0 & 2 & 4.7 \\
\hline Smartphone & 11 & 25.6 & 12 & 27.9 & 5 & 11.6 & 2 & 4.7 & 13 & 30.2 \\
\hline Laptop computer & 1 & 2.3 & 3 & 7.0 & 6 & 14.0 & 5 & 11.6 & 27 & 62.8 \\
\hline Desktop computer & 1 & 2.3 & 3 & 7.0 & 8 & 18.6 & 4 & 9.3 & 27 & 62.8 \\
\hline Photocopier & 2 & 4.7 & 2 & 4.7 & 4 & 9.3 & 5 & 11.6 & 30 & 69.8 \\
\hline Scanner & 3 & 7.0 & 0 & 0.00 & 0 & 0.00 & 5 & 11.6 & 35 & 81.4 \\
\hline Flash disk & 2 & 4.7 & 5 & 11.6 & 2 & 4.7 & 3 & 7.0 & 31 & 72.1 \\
\hline Printer & 2 & 4.7 & 2 & 4.7 & 1 & 2.3 & 6 & 14.0 & 32 & 74.4 \\
\hline
\end{tabular}

ICT, information and communication technology.

TABLE 2: Competence of health surveillance assistants in using web applications ( $n=43)$.

\begin{tabular}{|c|c|c|c|c|c|c|c|c|c|c|}
\hline \multirow[t]{2}{*}{ Web applications } & \multicolumn{2}{|c|}{ Very good } & \multicolumn{2}{|c|}{ Good } & \multicolumn{2}{|c|}{ Average } & \multicolumn{2}{|c|}{ Poor } & \multicolumn{2}{|c|}{ Not competent at al } \\
\hline & $f$ & $\%$ & $f$ & $\%$ & $f$ & $\%$ & $f$ & $\%$ & $f$ & $\%$ \\
\hline $\begin{array}{l}\text { District health } \\
\text { information system }\end{array}$ & 16 & 37.2 & 1.00 & 2.3 & 3 & 7.0 & 3 & 7.0 & 20 & 46.5 \\
\hline WhatsApp & 13 & 30.2 & 11 & 25.6 & 5 & 11.6 & 4 & 9.3 & 10 & 23.3 \\
\hline Twitter & 1 & 2.3 & 1 & 2.3 & 2 & 4.7 & 4 & 9.3 & 35 & 81.4 \\
\hline Skype & 2 & 4.7 & 0 & 0.00 & 4 & 1.00 & 5 & 11.6 & 35 & 81.4 \\
\hline SMS & 15 & 34.9 & 6 & 14.0 & 1 & 2.3 & 3 & 7.0 & 18 & 41.9 \\
\hline Internet & 1 & 2.3 & 3 & 7.0 & 4 & 9.3 & 3 & 7.0 & 32 & 74.4 \\
\hline Email & 0 & 0.00 & 5 & 11.6 & 6 & 14.0 & 5 & 11.6 & 27 & 62.8 \\
\hline Cloud computing & 3 & 7.0 & 0 & 0.0 & 3 & 7.0 & 3 & 7.0 & 34 & 79.1 \\
\hline
\end{tabular}

SMS, short messaging system.

\section{Purposes that health surveillance assistants use information and communication technologies for}

The HSAs were asked to indicate the purposes they accomplished using ICTs in both their personal and work spaces. The purpose was to identify the relationship between the respondents' use of ICTs in personal space and work space. Findings are presented in Table 3 . As can be observed in Table 3, in general, HSAs used these applications for chatting with friends, communicating, interacting with friends, for data entry, sending reports, searching health information reports and reading news. Despite Jimoh et al. (2012) report that the mobile sector has satisfactorily flourished in most part of subSaharan Africa, our study shows that use of some ICTs such as Twitter amongst HSAs is still low in Malawi. The study revealed that SMS, Facebook and WhatsApp are the most used applications in personal work space. Despite prior reports that penetration of smartphones has tremendously contributed to awareness of some web-dependent technologies such as Facebook and WhatsApp in Malawi (see Chawinga \& Zinn 2015; Chawinga \& Zozie 2016), the study showed that some web-based technologies such as Twitter are not used by HSAs. The study revealed further that web-based applications, such as Facebook and WhatsApp, which HSAs are competent in using, are used to accomplish work-related activities on a very small scale. This is attributed to the fact that social networks are commonly perceived to be used for informal communication and discourage HSAs to use them for formal work purposes.

\section{Benefits of information and communication technologies}

Various prior researchers such as Lucas (2008), Miah et al. (2016), Nair (2014) and Ruxwana et al. (2010) have reported
TABLE 3: Use of information and communication technology applications in personal and work spaces $(n=43)$.

\begin{tabular}{|c|c|c|c|c|}
\hline Use & Purpose & ICTs & $f$ & $\%$ \\
\hline \multirow[t]{12}{*}{ Personal } & Chatting & Facebook & 17 & 39.5 \\
\hline & & WhatsApp & 19 & 44.2 \\
\hline & & SMS & 1 & 2.3 \\
\hline & Communication & Facebook & 6 & 14.0 \\
\hline & & WhatsApp & 11 & 25.6 \\
\hline & & SMS & 34 & 79.1 \\
\hline & & Email & 9 & 20.9 \\
\hline & News updates & Internet & 6 & 14.0 \\
\hline & & Facebook & 1 & 2.3 \\
\hline & & Twitter & 1 & 2.3 \\
\hline & Sending reports & WhatsApp & 1 & 2.3 \\
\hline & Interaction & SMS & 1 & 2.3 \\
\hline \multirow[t]{14}{*}{ Work } & Communication & Facebook & 14 & 32.6 \\
\hline & & WhatsApp & 18 & 41.9 \\
\hline & & SMS & 32 & 74.4 \\
\hline & & Email & 7 & 16.3 \\
\hline & & Skype & 1 & 2.3 \\
\hline & & Internet & 5 & 11.6 \\
\hline & News updates & Facebook & 1 & 2.3 \\
\hline & & Twitter & 1 & 2.3 \\
\hline & Sending reports & WhatsApp & 7 & 16.3 \\
\hline & & SMS & 1 & 2.3 \\
\hline & & DHIS & 4 & 9.3 \\
\hline & Interaction & SMS & 1 & 2.3 \\
\hline & Data entry & DHIS & 12 & 27.9 \\
\hline & Searching reports & DHIS & 1 & 2.3 \\
\hline
\end{tabular}

SMS, short messaging system; DHIS, district health information systems; ICT, information and communication technology.

that there are several benefits of using ICTs in the health sector. Similarly, as can be seen in Table 4, the findings of the current study show that 38 (88.4\%) HSAs 'strongly agree' or 'agree' that ICTs provide quick access to up-to-date 
TABLE 4: Benefits of using information and communication technologies in work spaces $(n=43)$.

\begin{tabular}{|c|c|c|c|c|c|c|c|c|c|c|}
\hline \multirow[t]{2}{*}{ Benefits } & \multicolumn{2}{|c|}{ Strongly agree } & \multicolumn{2}{|c|}{ Agree } & \multicolumn{2}{|c|}{ Disagree } & \multicolumn{2}{|c|}{ Strongly disagree } & \multicolumn{2}{|c|}{ Not sure } \\
\hline & $f$ & $\%$ & $f$ & $\%$ & $f$ & $\%$ & $f$ & $\%$ & $f$ & $\%$ \\
\hline Quick access to current information & 25 & 58.1 & 10 & 23.3 & 0 & 0.0 & 0 & 0.0 & 8 & 18.6 \\
\hline Improve quality of health services & 26 & 60.5 & 12 & 27.9 & 0 & 0.0 & 1 & 2.3 & 4 & 9.3 \\
\hline Enhance knowledge and skills of health professionals & 20 & 46.5 & 14 & 32.6 & 1 & 2.3 & 0 & 0.0 & 8 & 18.6 \\
\hline Help to improve communication & 26 & 60.5 & 10 & 23.3 & 0 & 0.0 & 0 & 0.0 & 7 & 16.3 \\
\hline Help reduce workload of health professionals & 21 & 48.8 & 11 & 25.6 & 2 & 4.7 & 0 & 0.0 & 9 & 20.9 \\
\hline
\end{tabular}

information, improve quality of health services, enhance knowledge and skills of health professionals, help to improve communication and help to reduce workload of health professionals. The results strongly align with other studies. For example, a study by Omona and Ikoja-Odongo (2006) revealed that all respondents concurred that using ICTs improved accessibility, dissemination and quality of health information by presenting current information and data; eliminate geographical boundaries, source of up-to-date global information on health; provide quick access of required information sources; lead to improved knowledge on health and increase desire in learning as well as staring research. It is clear that by using these ICTs, HSAs perceive them as useful and therefore are motivated to adopt them. These findings conform to the aspect of the TAM which proposes that people will be encouraged to use a technology if it adds value (usefulness) to their work activities.

\section{Challenges health surveillance assistants face in adopting and using information and communication technologies}

The HSAs were asked the challenges they face in adopting and using ICTs. The findings are presented in Table 5. Challenges faced in the effective deployment of ICTs in the health sector are highlighted in various scholarly literature such as those by Jimoh et al. (2012), Lucas (2008), Omona and Ikoja-Odongo (2006) and Ruxwana et al. (2010). Results of the current study showed that $35(81.4 \%)$ HSAs 'strongly agree' or 'agree' that they do not effectively use these technologies because of high cost of ICT gadgets, high cost of Internet bundles, lack of training in ICT applications and lack of support from health administrators in arranging ICT training for HSAs. It is not surprising that $37(86.0 \%)$ did not consider unavailability of electricity, lack of interest, fear of ICT applications and long distance to the nearest Internet café as problems. The proliferation of power banks and solar energy in most of the rural areas in Malawi has reduced overdependence on electricity. Power banks allow storage of electrical energy and will then later be used to charge up a mobile device. By interpreting these findings through the lens of the adopted model, it is possible to understand the reasons why some HSAs have not fully adopted ICTs for work purposes. In the model, Davis (1989:3) argues that 'perceived usefulness' and 'perceived ease of use' influence the users' behavioural intentions towards accepting or rejecting a new technology. In the present study, HSAs have not fully accepted these technologies because of high cost of ICT gadgets, high cost of Internet bundles, inadequate training in ICT applications and lack of support from the administration in training HSAs.
TABLE 5: Challenges health surveillance assistants face in using information and communication technologies in community health $(n=43)$.

\begin{tabular}{lcccccc}
\hline Challenges & \multicolumn{2}{c}{ Yes } & & \multicolumn{2}{c}{ No } \\
\cline { 2 - 3 } \cline { 7 - 8 } & $f$ & \% & & $f$ & $\%$ \\
\hline High cost of gadgets & 33 & 76.7 & & 10 & 23.3 \\
High cost of credit or bundles & 30 & 69.8 & & 13 & 30.2 \\
Unavailability of electricity & 19 & 44.2 & & 24 & 55.8 \\
Inadequate training in ICT applications & 35 & 81.4 & & 8 & 18.6 \\
Lack of ICT infrastructure & 29 & 67.4 & & 14 & 32.6 \\
Lack of support from the administration & 25 & 58.1 & & 18 & 41.9 \\
Lack of interest & 6 & 14.0 & & 37 & 86.0 \\
Fear of ICT applications & 7 & 16.3 & & 36 & 83.7 \\
Long distance to the nearest ICT café or centre & 18 & 41.9 & & 25 & 58.1 \\
\hline
\end{tabular}

ICT, information and communication technologies.

So, it is clear to see that some HSAs perceive ICTs as not easy to use, hence their unwillingness to accept them. The results of the current study align with the study of Ruxwana et al. (2010), which identified the same barriers to adoption of ICTs for purposes of e-health. Results of the current study ascertain that the adoption level of ICTs by HSAs is not satisfactory because various web-based technologies such as Twitter are yet to be embraced by these HSAs.

\section{Limitations of the study}

The study was limited to HSAs from two hospitals. The study could have been more informative if it included other health stakeholders such as the populations the HSAs serve, HSAs' supervisors and $\mathrm{MoH}$ officials. For triangulation purposes, future research should consider expanding their scope to include various health players in the health sector.

\section{Conclusion and recommendations}

Using the TAM (Davis 1989), the study set out to investigate the use of ICTs by HSAs at two hospitals in Malawi. The study revealed that HSAs have adopted some ICTs which they are using in their personal and work activities. The study found that, while mobile phones were the most common forms of ICT device used by HSAs, Facebook and WhatsApp were the most adopted and used applications by the respondents. Worth mentioning is that despite being popular amongst HSAs, Facebook and WhatsApp were mostly used for personal purposes; only a few HSAs used these social networks for work-related activities. The study further showed that communication, chatting, sending reports and news updates are key purposes HSAs use ICTs for. The study showed that use of ICTs by HSAs came along with some benefits, which included quick access to current information, improved health services and quick communication. The use of ICTs by HSAs is not short of challenges because the study revealed that high 
cost of ICT gadgets, high cost of Internet bundles and lack of ICT skills negatively affected assimilation of ICTs by HSAs. In a nutshell, the study has shown that, regardless of perceivable hindrances associated with use of ICTs, HSAs use some ICTs in their work and personal activities. To this end, our conclusion is that use of ICT in community health is slowly but surely possible. In accordance with the results of this study, we make the following recommendations:

- As the study revealed that most HSAs are competent in using various web-based technologies but are using them for work purposes, we recommend that the Malawi Government through the $\mathrm{MoH}$ should promote the use of ICTs to HSAs in delivery of health services in rural areas.

- As one of the key challenges according to the study is high costs of ICT gadgets such as mobile phones, we recommend that the $\mathrm{MoH}$ and other health stakeholders should consider purchasing and distributing important gadgets to the HSAs to be used for work purposes.

- The MoH and other health stakeholders should team up with network service providers in Malawi to offer subsidised and affordable Internet data bundles to HSAs as one way of encouraging them to use ICTs in their work activities.

- The MoH should collaborate with universities such as the Department of Information and Communication Technology at Mzuzu University to offer customised ICT training to HSAs.

\section{Area for further study}

We propose that as this study has shown that use of ICTs is possible in the delivery of health services in rural areas, there is need to carry out a longitudinal or multiphase study where HSAs need to be provided with technological resources such as smartphones and assess the impact of these ICT gadgets on the delivery of health services in rural areas.

\section{Acknowledgements}

This article was extracted from a master's dissertation submitted in the Programme of Information Technology in Amity University in 2017.

\section{Competing interests}

The authors declare that they have no financial or personal relationships that may have inappropriately influenced them in writing this article.

\section{Authors' contributions}

C.N. and W.D. contributed equally to the writing of this article.

\section{References}

Ahlan, A.R. \& Ahmad, B.I.E., 2014, 'User acceptance of health information technology (HIT) in developing countries: A conceptual model', Procedia Technology 16, 1287-1296. https://doi.org/10.1016/j.protcy.2014.10.145

Aliaga, M. \& Gunderson, B., 2000, Interactive statistics, Prentice Hall, Saddle River, NJ. Chaputula, A.H., 2012, 'State, adoption and use of ICTs by students and academic staff at Mzuzu University, Malawi', Program: Electronic Library and Information Systems 46(4), 364-382. https://doi.org/10.1108/00330331211276477
Chawinga, W.D., 2016, 'Teaching and learning 24/7 using Twitter in a university classroom: Experiences from a developing country', E-Learning and Digital Media 13(1-2), 45-61. https://doi.org/10.1177/2042753016672381

Chawinga, W.D. \& Zinn, S., 2015, 'Lecturers' use of Web 2.0 in the Faculty of Information Science and Communications at Mzuzu University', Malawi', Mousaion: South African Journal of Information Studies 33(4), 62-85.

Chawinga, W.D. \& Zinn, S., 2016, 'Use of Web 2.0 by students in the Faculty of Information Science and Communications at Mzuzu University, Malawi' South African Journal of Information Management 18(1). https://doi.org/10.4102/sajim. v18i1.694

Chawinga, W.D. \& Zozie, P., 2016, 'Information needs and barriers to information sources by open and distance learners: A case of Mzuzu University, Malawi', South African Journal of Information Management 18(1), a692. https://doi.org/10.4102/ sajim.v18i1.692

Chow, M., Herold, D.K., Choo, T.M. \& Chan, K., 2012 'Extending the technology acceptance model to explore the intention to use second life for enhancing healthcare education', Computers \& Education 59(4), 1136-1144. https://doi.org/ healthcare education', Computers $\&$.
10.1016/j.compedu.2012.05.011

Christian Health Association of Malawi (CHAM), 2017, About CHAM, viewed 02 February 2017, from http://www.cham.org.mw/about-cham.html

Creswell, J.W., 2009, Research design: Qualitative, quantitative, and mixed methods approaches, 3rd edn., Sage, London.

Davis, F., 1989, 'Perceived usefulness, perceived ease of use, and user acceptance of information technology', MIS Quarterly 13(2), 319-339. https://doi.org/10.2307/ 249008

Douglas, G.P., Gadabu, O.J., Joukes, S., Mumba, S., McKay, M.V., Ben-Smith, A., et al., 2010, 'Using touchscreen electronic medical record systems to support and monitor national scale-up of antiretroviral therapy in Malawi', PLoS Med 7(8), e1000319. https://doi.org/10.1371/journal.pmed.1000319

Facebook, 2017, Free basics platform, viewed 03 February 2017, from https:// developers.facebook.com/docs/internet-org

Gagnon, M.P., Orruño, E., Asua, J., Abdeljelil, A.B. \& Emparanza, J., 2012, 'Using a modified technology acceptance model to evaluate healthcare professionals adoption of a new telemonitoring system', Telemedicine and e-Health 18(1), 54-59. https://doi.org/10.1089/tmj.2011.0066

Holden, R.J. \& Karsh, B.T., 2010, 'The technology acceptance model: Its past and its future in health care', Journal of Biomedical Informatics 43(1), 159-172. https:// doi.org/10.1016/j.jbi.2009.07.002

Jimoh, L., Pate, M.A., Lin, L. \& Schulman, K.A., 2012, 'A model for the adoption of ICT by health workers in Africa', International Journal of Medical Informatics 81(11) 773-781. https://doi.org/10.1016/j.ijmedinf.2012.08.005

Kadzandira, J.M. \& Chilowa, W.R., 2001, The role of heath surveillance assistants in the delivery of health services and immunisation in Malawi, University of Malawi, Center for Social Research, Malawi.

Kok, M.C. \& Muula, A.S., 2013, 'Motivation and job satisfaction of health surveillance assistants in Mwanza, Malawi: An explorative study', Malawi Medical Journa 25(1), 5-11.

Lucas, H., 2008, 'Information and communications technology for future health systems in developing Countries', Social Science \& Medicine 66(10), 2122-2132. https://doi.org/10.1016/j.socscimed.2008.01.033

Luke International, 2016, Online resources, viewed 11 January 2017, from http:// lukeinternational.no/malawi/

Miah, S.J., Hasan, J. \& Gammack, J.G., 2016, 'On-cloud healthcare clinic: An e-health consultancy approach for remote communities in a developing country', Telematics and Informatics 34(1), 311-322. https://doi.org/10.1016/j.tele.2016. 05.008

Ministry of Health (MoH), 2011, Malawi Health Sector Strategic Plan 2011-2016, viewed 23 January 2017, from http://www.nationalplanningcycles.org/sites/ default/files/country_docs/Malawi/2_malawi_hssp_2011_-2016_final_ document_1.pdf

Mouton, J., 2001, How to succeed in your master's and doctoral studies: A South African guide and resource book, Van Schaik, Pretoria.

Nair, P., 2014, 'ICT based health governance practices: The Indian experience', Journal of Health Management 16(1), 25-40. https://doi.org/10.1177/09720634135 18678

Omona, W. \& Ikoja-Odongo, R., 2006, 'Application of information and communication technology (ICT) in health information access and dissemination in Uganda', Journal of Librarianship and Information Science 38(1), 45-55. https://doi.org/ 10.1177/0961000606060959

Organization for Economic Cooperation and Development (OECD), 2017, Improving health sector efficiency: The Role of information and communication technologies, viewed 06 January 2017, from https://usoecd.usmission.gov/mission/overview. html

Patton, M.Q., 2002, Qualitative evaluation and research methods, Sage, Newbury Park, CA.

Quaglio, G., Dario, C., Karapiperis, T., Delponte, L., Mccormack, S., Tomson, G., et al., 2016, 'Information and communications technologies in low and middle-income 2016, 'Information and communications technologies in low and middle-income
countries: Survey results on economic development and health', Health Policy and Technology 5(4), 318-329. https://doi.org/10.1016/j.hlpt.2016.07.003

Ramachandran, D., Canny, J., Das, P.D. \& Cutrell, E., 2010, 'Mobilizing health workers in rural India', in Proceedings of the SIGCHI Conference on Human Factors in Computing Systems, ACM, Atlanta, GA, April 10-15, 2010, pp. 1889-1898. 
Ruxwana, N.L., Herselman, M.E. \& Conradie, D.P., 2010, 'ICT applications as e-health solutions in rural healthcare in the Eastern Cape Province of South Africa', Health 831003900104

Shekar, M. \& Otto, K., 2014, ICTs for health in Africa, viewed 20 January 2017, from http://siteresources.worldbank.org/EXTINFORMATIONANDCOMMUNICATIONAN DTECHNOLOGIES/Resources/282822-1346223280837/Health.pdf

Voluntary Service Overseas (VSO) Malawi, 2011, Improving management and supervision for Health Surveillance Assistants in Malawi, viewed 20 January 2017 from http://www.who.int/workforcealliance/forum/2011/hrhawardscs13/en/
World Health Organization (WHO), 2004, Strategy 2004-2007. e-Health for health-care delivery, viewed 20 January 2017, from http://www.who.int/eht/en/eHealth delivery,
HCD.pdf.

World Health Organization (WHO), 2006, eHealth tools and services: Needs of the member states. Report of the WHO Global Observatory for eHealth, WHO, Geneva, viewed 21 January 2017, from http://apps.who.int/medicinedocs/ documents/s16468e/s16468e.pdf

Yarbrough, A.K. \& Smith, T.B., 2007, 'Technology acceptance among physicians: A new take on TAM', Medical Care Research and Review 64(6), 650-672. https://doi. org/10.1177/1077558707305942 